\title{
Coulisses
}

Revue de théâtre

12 | Printemps 1995

Varia

\section{Critique du spectacle La Cagnotte de Labiche}

\author{
Gisèle G. Holtzer
}

\section{(2) OpenEdition}

Journals

Édition électronique

URL : http://journals.openedition.org/coulisses/3378

DOI : $10.4000 /$ coulisses.3378

ISSN : 2546-9460

\section{Éditeur}

Presses universitaires de Franche-Comté

\section{Édition imprimée}

Date de publication : 1 mai 1995

Pagination : 58-60

ISSN : 1150-594X

\section{Référence électronique}

Gisèle G. Holtzer, «Critique du spectacle La Cagnotte de Labiche », Coulisses [En ligne], 12 | Printemps 1995, mis en ligne le 15 mars 2019, consulté le 31 octobre 2019. URL : http://journals.openedition.org/ coulisses/3378; DOI : 10.4000/coulisses.3378

Ce document a été généré automatiquement le 31 octobre 2019

Coulisses 


\title{
Critique du spectacle La Cagnotte de Labiche
}

\author{
Gisèle G. Holtzer
}

La Cagnotte de Labiche a été représentée les 29-30 et 31 mars 1995 au Théâtre municipal de Besançon, dans une mise en scène de Jean-Luc Lagarce.

\section{La Cagnotte}

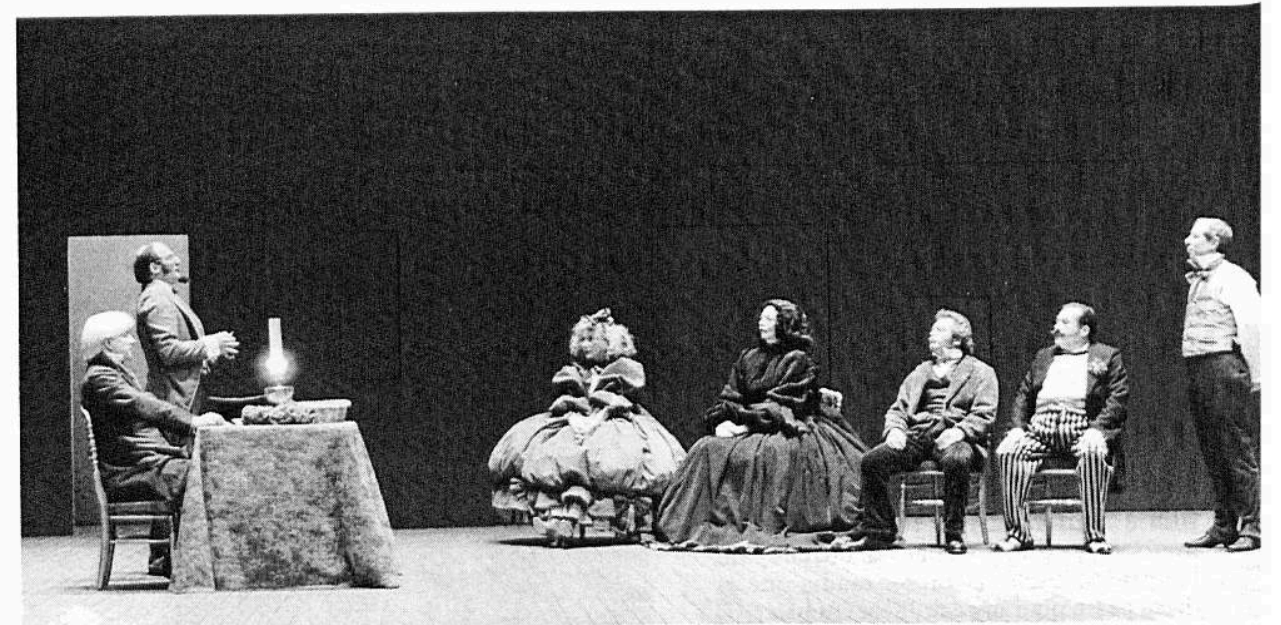

(C) Photo Brigitte ENGUERAND

1 La Cagnotte, comédie-vaudeville, a été créée au Palais-Royal le 22 février 1864. La pièce figure parmi les grands succès de Labiche: ainsi, entre 1864 et 1892, elle n'a pratiquement jamais quitté l'affiche du Palais-Royal. Aujourd'hui, Labiche, catalogué dans le théâtre de boulevard, est relativement négligé, même si le théâtre amateur lui fait encore la part belle. On peut se demander ce qui, dans cette comédie "à ressorts » mettant en scène de petits bourgeois de province venus à Paris " mener tous le train ", a pu séduire J.-L. Lagarce dont la réputation s'est construite dans un cercle très éloigné 
du boulevard. Désir d'affronter le "vieux" théâtre avec un autre regard? Volonté d'échapper aux cloisonnements et de (se) surprendre dans un genre nouveau pour lui ?

2 Certains thèmes de la pièce sont intemporels : le rapport de la société à l'argent a des échos aujourd'hui (dans La Cagnotte, on ne cesse de compter, discuter les prix, chercher à « arnaquer » l'autre...) ; l'opposition province - Paris, évoquée par Labiche d'un trait appuyé, peut encore fonctionner, mais avec la province très "profonde "; le thème de l'innocence confrontée à la justice résonne fortement à nos oreilles averties, telle la réplique de Champbourcy:

Ne crains rien, ma fille, l'homme intègre ne craint pas de se présenter devant la justice de son pays... Marchons! (II, 10)

D'autres aspects passent moins bien. La pièce est inégale, avec de grandes accélérations et des retombées. Il est vrai que le théâtre de boulevard a façonné l'image d'un Labiche auteur de pièces au rythme vif, aussi le spectateur s'attend-il à une action rapide enchaînant les épisodes à une cadence soutenue. La première scène qui voit les personnages jouer à la bouillotte (jeu de cartes dont les règles restent hermétiques) a un rythme lent ; elle est presque jouée en temps réel, les protagonistes s'inquiétant de l'heure, de l'écoulement du temps de façon quasi obsessionnelle :

Félix à Léonida : «Dans cinq minutes je vous cède la place »

Léonida : "Neuf heures et quart... Mon tour est arrivé »

Blanche à Félix : « Vous allez être un quart d'heure à vous ennuyer »

Blanche: «Papa, il est neuf heures et demie».

4 L'acte II, dans la scène du restaurant, apporte une accélération rythmique avec une suite d'entrées et de sorties, d'épisodes comiques (exemple la description des plats comme le Tournedos à la plénipotentiaire qui nous rappelle l'afféterie de certaines cartes de restaurant). Cependant, à la représentation, la pièce ne semble pas avoir trouvé son rythme dans toutes ses parties. Il faut dire que le public actuel ne réagit sans doute pas à toute occasion comme celui de Labiche et que tel épisode qui amusait l'un ennuie peut-être parfois l'autre.

5 Le décor-salon de province de Champbourcy et salon parisien de Cocarel - se caractérise par une sobriété manifeste comparée aux indications de l'auteur. L'espace intérieur chez Labiche est espace rempli, comblé de meubles et d'objets: "Tables, chaises, lampes, etc.; cheminée au premier plan à droite, table de jeu à gauche, guéridon à droite, chaises couvertes de housse, secrétaire, table, etc. » (didascalies, I, 1). J.-L. Lagarce, qui n'aime visiblement pas les effets de surcharge, supprime tout accessoire décoratif, ce qui laisse d'ailleurs davantage de champ aux personnages. L'élimination des objets inutiles à l'action a l'intérêt d'éviter les longs changements de décor; ici, les transformations se font à vue, à scène ouverte, sans ruptures pour le spectateur.

6 Comédie-vaudeville, La Cagnotte comporte des chansons selon la loi du genre. Pas moins de dix chansons ponctuent différents épisodes : dépouillement du vote pour décider ce que l'on fera du produit de la cagnotte $(1,2)$, départ pour la visite de la colonne Vendôme (11,3), arrivée au bureau de police (III, 1)... Parmi les musiques dans la note vaudevillesque, le spectateur a la surprise d'entendre l'air de Carmen et des fragments wagnériens (La Walkyrie), bribes musicales contemporaines de Labiche qui créent un agréable contraste culturel, d'autant qu'ils servent de support à des textes au prosaïsme affirmé : 
Allons visiter la colonne!

Dans notre ardeur à promener

Faisons en sorte que personne

Ne retarde le déjeuner.

7 Jouer du Labiche est pour le comédien, en danger de forcer le ton, une épreuve redoutable. Le vaudeville oblige à la rigueur, à la précision dans le jeu. L'un des aspects les plus difficiles à maîtriser est la voix : savoir placer sa voix, en contrôler la force, rester en somme dans le registre du naturel n'est pas chose aisée. Si dans le jeu corporel, les comédiens ont démontré finesse et mesure, la performance vocale en revanche a parfois été - du moins m'a paru être - en deçà (voix trop forte, poussée dans les aigus). C'est la seule vraie critique à faire à un spectacle dont les « défauts » tiennent peut-être davantage à la pièce elle-même qu'à la mise en scène. 